\title{
PROVÉRBIOS E TRADUÇÃO ${ }^{1}$
}

Martha Steinberg ${ }^{*}$

RESUMO: A autora acredita que para se traduzir um provérbio é necessário conhecer sua estrutura lingüística, seus tipos e emprego. Com alguns exemplos, esses pontos são discutidos aqui. UNITERMOS: Tradução; provérbios; expressões idiomáticas.

Archer Taylor diz que a definição de provérbio é complicada demais para valer a pena (Dundes, 1975). Diz também que todo mundo sabe o que é um provérbio, de modo que não há necessidade de defini-lo. Porém, como é que reconhecemos que um determinado dizer é um provérbio? Acreditamos que uma descrição de sua estrutura lingüística, conteúdo, tipos de mensagem e usos poderá ajudar a reconhecê-lo, bem como expor os desafios que coloca para um tradutor.

Charles Kreidler (Kreidler, 1989) diz que um texto pode ser qualquer coisa, desde um provérbio até uma peça teatral. Fica implícita aí a idéia de que um provérbio é um texto completo. Um texto minimo, mas, como qualquer outro texto, analisável
ABSTRACT: The author believes that in order to translate a proverb one should be aware of some of its characteristics, such as its linguistic structure, its types and usage. These points are discussed here with a few examples.

KEYWORDS: Translation; proverbs; idiomatic expressions.

em suas partes componenciais. É também um texto sem direitos autorais. Fruto da sabedoria popular, é de domínio público. Todos se apoderam desse texto para inseri-lo no seu sem pedir permissão a ninguém. À guisa de justificativa, muitas vezes usamno precedido de "minha mãe/avó já dizia ...", "como se dizia antigamente ...", "na minha terra se costuma dizer ...". Sendo um texto já pronto, inserido em outro, ele freqüentemente viola, com sua sintaxe e semântica o contexto de sua ocorrência. O exemplo clássico é $A$ stitch in time saves nine quando inserido num contexto que não seja o da costura .Nesse caso, ele deve ser tomado metaforicamente. Para citar um exemplo nosso, "Muita cozinheira entorna o caldo", num contexto não

1 Obs.: Este texto é parte de uma palestra proferida por ocasião do II ENCONTRO DE TRADUTORES da Associação ALUMNI, em São Paulo, em 8 de Novembro de 1993.

* Professora Títular de Lingua Inglesa, DLM/FFLCH/USP. 
culinário, estará ferindo o conjunto de sua ocorrência, com o vocabulário e com a semântica. A mensagem é entendida metaforicamente.

$O$ provérbio tem a característica de poder ocorrer tanto em linguagem literária quanto em linguagem técnica. Mesmo quando de criação literária, ele é freqüentemente empregado na linguagem técnica.

José Paulo Paes (Paes, 1990) chama a expressão idiomática metafórica de expressão proverbial. Não sem razão, pois a expressão proverbial pode se tornar, e freqüentemente o faz, provérbio propriamente dito. Uma expressão idiomática, especialmente a metafórica, tem como característica não poder ser traduzida pela soma de suas partes componenciais, ou seja, palavra por palavra. Sua tradução é feita por equivalência semântica. Outro detalhe é que a expressão idiomática não é um texto. Ela faz parte de um texto. "Chorar pela lua" é uma expressão idiomática. "Não adianta chorar pela lua" é um provérbio.

A forma na qual um texto se apresenta é de grande importância para o tradutor pois, via de regra, ele se especializa num determinado tipo. Em primeiro lugar, a grosso modo, ele trabalha com linguagem técnica ou literária. No primeiro caso, há um grande leque de atividades humanas que se expressam naquilo que se convencionou chamar de linguagem técnica. No segundo, há a considerar gênero e estilo. O provérbio, independentemente de sua mensagem e do texto no qual se insere, tem características estruturais que o aproximam do verso, pois faz uso dos mesmos artificios de linguagem, que lhe garantem a fluência prosódica, $\mathrm{e}$ fácil memorização. Vejamos os mais óbvios:

- aliteração: Live and learn. Na tradução ou equivalência - Viver é aprender - cla se perde em favor da rima.

- assonância: A rolling stone gathers no moss. $\mathrm{O}$ nosso equivalente - Pedra que rola não cria limo - parece ter optado por um verso branco.
- paralelismo: Out of sight, out of mind.- preservado no nosso equivalente "Longe dos olhos, longe do coração".

- repeticão: There is no fool like an old fool.traduzido para "Não há bobo como um bobo velho".

- rima: Man proposes, God disposes, também presente em nosso equivalente - "O homem propõe, Deus dispöe".

- paronomásia: Many a little makes a mickle, onde o jogo de palavras produz o efeito rítmico. $O$ nosso - De grão em grão a galinha enche o papo - serve-se da repetição.

- elipse: For want of a nail ... - equivalente ao nosso "Por falta de um prego ...", onde o restante da história que originou o provérbio é omitido.

Outro aspecto a ser lembrado e que já foi acima mencionado é o fato de ele ser introduzido por fórmulas estereotipadas tais como "as they say", "as the old saying goes", e os nossos "como já dizia minha mãe/avó", "como diz o ditado", ou ainda "na minha terra se diz". A estrutura sintática faz uso freqüente de condicionais - If the cap fits, wear it ("Se a carapuça serve, enfie na cabeça"), bem como de imperativos - Do as I say, not as I do ("Faça como digo, não como eu faço"). Muitos provérbios se iniciam com He that ..., It is .... Better..., There is ...(Aquele que/quem, É, É melhor, Há/Não há). Uma breve vista d'olhos nos exemplos citados nos mostra que a estrutura do provérbio é binária, de dois sintagmas correlatos (Gonçalves, 1977).

Quanto ao aspecto de seu conteúdo, o provérbio transmite:

- ensinamento ou constatação de fato: Health is better than wealth (A saúde é a melhor riqueza).

- advertência: He that sings on Friday will weep on Sunday (Quem ri na sexta chora no do- 
mingo"). Beware of a silent dog and still water (Guarda-te do homem que não fala e do cão que não ladra).

- consclho: Don't change horses midstream (Não se muda de cavalo no meio do banhado).

Os tipos de provérbios imbricam muitas vezes com 0 aspecto semântico:

- registram um fato baseado na experiência: $\mathrm{He}$ that has been bitten by a serpent is afraid of a rope (Gato escaldado tem medo de água fria).

- metafóricos: $A$ stitch in time saves nine. (É melhor prevenir que remediar).

- parodiados: A Company is known by the people it keeps (Uma Companhia se conhece pelas pessoas que mantém.), paródia de $A$ man is known by the company it keeps (Dize-me com quem andas e direi quem tu és); $A$ book in the hand is worth two on the shelf (Um livro na mão vale mais que dois na estante), paródia $\operatorname{de} A$ bird in the hand is worth two in the bush (Mais vale um pássaro na mão que dois voando).

- aparentemente contraditórios: Look before you leap (Faze pé atrás e melhor saltarás.) e $\mathrm{He}$ who hesitates is lost (Onça que dorme no ponto vira tapete).

De amplo emprego em todo tipo de texto ou discurso, o provérbio é usado para:

- reforçar um argumento: I told you, lies have short legs (Bem que eu dizia, mentira tem perna curta).

- invocar autoridade: Don't teach your grandmother to suck eggs (Não queira ensinar o padre nosso ao vigário).

- admoestar: Never ask pardon before you are accused. (Quem não tem culpa não pede desculpa).
- instruir: The exception proves the rule (A exceção prova a regra).

- aconselhar: Never put off till tomorrow what may be done today (Não deixe para amanhã o que você pode fazer hoje).

- prevenir: Where there is smoke, there is fire (Onde há fumaça há fogo).

$\dot{E}$ claro que cada um dos exemplos acima pode ser usado para cada uma das outras finalidades, pois é o contexto ou situação que determina a ocorrência.

A publicidade faz amplo uso de provérbios è expressões metafóricas. É nesse emprego que se encontra o maior desafio para o tradutor, pois a expressão no caso é alusiva a uma certa imagem ou gravura que reflete a própria figura de linguagem empregada. Há como que um trocadilho entre figura de linguagem e figura propriamente dita.

Assim, to spill the beans acompanhando uma ilustração de feijões sendo despejados para aludir ao fato de que está sendo revelado um segredo, o segredo do valor alimentício de feijoes, perde o sentido em português, pois a tradução da expressão é "dar com a língua nos dentes". A equivalência da expressão não condiz com a ilustração dos feijões sendo despejados.

A política não só cria expressões como parodia proverbios. To go on the stump. tem suas origens nas regióes rurais dos Estados Unidos, durante as campanhas presidenciais, quando os candidatos subiam a um stump, isto é, um toco de árvore para se fazerem ouvir. A atual situação política nacional já propiciou entre nós "Quem vê cara não vê corrupção", que é uma paródia de "Quem vê cara não vê coração".

A música popular não só emprega, mas também cria expressões e provérbios. É curioso o caso da uma expressão que se popularizou com um filme no qual Doris Day cantava "Che sera, sera" (What will be, will be).E um provérbio ainda muito usado entre os norte-americanos. $O$ interessante é que ele 
é semi-italiano, semi-espanhol, pois che é italiano e sera é espanhol.

Os nossos caminhoneiros transportam nos pára-choques de seus veículos jocosas expressðes que nos falam de sua sabedoria. E aqui já estamos no âmbito do folclore, isto é, da criação popular, que é a origem por excelência desse tipo de discurso/texto. É a expressão da cultura do povo.

O provérbio frequientemente é aludido, isto é, faz-se a ele uma referência e é preciso conhecê-lo para entender as implicações dessa alusão. Um provérbio bastante aludido entre nós ć "Se a carapuça servir enfie na cabeça", em situações onde a carapuça justamente serviu para alguém que confessa : "... enfiei a carapuça até a orelha".

Não só provérbios, mas também expressð̃es metafóricas são aludidas. Em recente matéria publicada pelo jornal O Estado de São Paulo (Gussow, 1993) o texto sobre o ator inglês Sir John Gielgud, na tradução, dizia que ele era famoso pelas suas gafes conhecidas como "tijolos de Gielgud", numa alusão à expressão inglesa to drop a brick, que significa cometer uma gafe ou dar uma rata.

A literatura inglesa é rica em provérbios e expressões metafóricas. Seu maior bardo e dramaturgo de todos os tempos - Shakespeare - criou expressões que posteriormente se popularizaram e muitas vezes se transformaram em provérbios. Brevity is the soul of wit (A brevidade é a alma do chiste); Something is rotten in the reign of Denmark (Há algo podre no reino da Dinamarca); to the manner born (ser feito/talhado para alguma coisa, ter nascido para); Hoist with his own petard (cuspir para o alto, o tiro sair pela culatra) são criações que aparecem em Hamlet. Para quem não conhece o fato, a peça pode parecer uma porção de clichês.

A cultura de um povo é estudada em padróes de comportamento. Segundo Lado (Lado, 1960), esses padrões têm características que permitem serem tratadas como unidades. Se tomarmos o provérbio como uma unidade de cultura, veremos que ele pode ser igual, parecido ou diferente de uma outra cultura com a qual esteja sendo comparado.
Essas diferenças ou semelhanças se referem à forma, à mensagem, à figura de linguagem. A sua distribuição, isto é, o seu emprego também pode diferir. Já foi amplamente dito que o subconsciente coletivo dos povos está dormente nas estruturas profundas. Ao se manifestar nas estruturas de superficie, ele assume formas relacionadas com a cultura em questão. Assim, se tomarmos o provérbio inglês Do not put the cart before the horse, veremos que o equivalente em língua portuguesa Não coloque o carro diante dos bois - difere em um item lexical. Para traduzir, teremos que respeitar o léxico, portanto cavalo e não bois. Se buscarmos o equivalente, perdemos o traço cultural. Mas a mensagem está preservada na equivalência. Isto acontece não apenas com línguas diferentes, mas nas variantes de um mesmo idioma. $\mathrm{O}$ provérbio em lingua inglesa $A$ bird in the hand is worth two in the bush (Mais vale um pássaro na mão que dois voando) para os irlandeses, ainda em lingua inglesa, é $A$ trout in the pot is better than a salmon in the sea (Uma truta na panela é melhor que um salmão no mar). Embora diferindo na forma, a mensagem e a distribuição são as mesmas. Já não acontece 0 mesmo com $A$ rolling stone gathers no moss. Para os ingleses, as pedras de um riacho ramente se movem e por isso criam limo, interpretado como prosperidade, riqueza. $O$ mesmo provérbio para os escoceses assume uma semântica diferente. A pedra a que se referem é um cilindro de pedra, de uso industrial. Se ficar parada cria limo, isto ć, deixa de trabalhar, dá prejuízo. Não basta, portanto, traduzir ou encontrar um equivalente. É preciso conhecer o seu uso.

Os provérbios são também aparentemente contraditórios. One is never too old to learn (Nunca é tarde para aprender) e You cannot teach an old dog new tricks (Papagaio velho não aprende a falar) aparentemente se contradizem. Na verdade, são empregados em situações diferentes. $\mathrm{O}$ primeiro para encorajar alguém que se supõe muito velho para aprender alguma coisa e o segundo para desculpar alguém mais idoso por não ter conseguido 
aprender algo. Cada um deles está na realidade desempenhando o seu papel social.

As coletâneas de provérbios costumam apresentá-los em ordem alfabética de um de seus elementos, ou ainda organizados em temas. São estes que justamente proporcionam o estudo do contraste entre culturas. Os temas podem ser de um de seus elementos componenciais, ou de seus referidos, de suas imagens. Assim é que temos provérbios sobre bichos, homens, mulheres, amor, ciúme, morte, inveja, etc.

Tanto provérbios quanto expressões proverbiais podem ser eufemísticos ou disfemisticos. Os primeiros amenizam uma situação ou fato com palavras menos realistas, enquanto que os últimos os tornam pejorativos. Um tema muito em voga na literatura atualmente é o da mulher. Um levantamento dos provérbios em lingua inglesa (Steinberg et al., trabalho em andamento) demonstrou que ela é tagarela, perigosa, falsa, vaidosa, preguiçosa, voluntariosa, má, gananciosa , perdulária, inconstante, sem inteligência, impulsiva, astuta, inferior ao homem, imperfeita. São todos disfemísticos. Em língua portuguesa ela não é nada melhor: perigosa, falsa, tagarela, leviana, sem inteligência, metida a sabida, calculista, voluntariosa. A pobre é também um mero objeto dos homens, que não só form autores dos disfemismos, mas também de outros provérbios que ensinam, dão conselhos de como se deve tratar a mulher. Poucas são as correspondências nas duas línguas, apesar da coincidência de temas.

Outro tema rico em provérbios e expressões proverbiais é o da morte (Camargo e Steinberg, 1989). Aqui constatamos que os eufemismos podem ser agnupados em alguns campos diferentes. Entre eles, temos o religioso. Em língua inglesa:

to join the immortals (The Pilgrim's Progress, obra de John Bunyan, século XVII) = juntar-se aos imortais;

\begin{abstract}
to have one 's name inscribed in The Book of Life (serviços religiosos judaicos) $=$ ter o seu nome inscrito no Livro da Vida;

to be in Abraham's bosom (Velho Testamento) $=$ estar no seio de Abraão.
\end{abstract}

São eufemismos que revelam uma sociedade familiarizada com a Bíblia, e também com o substrato judaico. Já em português, dizemos:

$$
\begin{aligned}
& \text { cumprir a vontade de Deus } \\
& \text { ajustar contas com o Divino } \\
& \text { entregar a alma ao criador }
\end{aligned}
$$

Embora de cunho religioso, não há alusão a nenhuma seita religiosa.

A morte é também vista como uma viagem:

to cross the river Jordan
to go to one's long home (Eclesi-
astes 12:5)
to buy a one way ticket
to go up Salt River
to pay Saint Peter a visit
to go across the creek

Em português encontramos:

deixar o mundo dos vivos

fazer a viagem sem volta

fazer a última viagem

tirar o passaporte

ir para a cidade dos pés juntos

ir para o beleléu

partir desta para a melhor

ir ver o céu por dentro

Ainda outras se referem a jogos de cartas:

to throw up the cards

to be trumped 
No mesmo campo semântico, em português encontramos:

\section{bater o trinta e um bater a canasta}

Outros disfemismos incluem:

to kiss the ground (beijar o chão) to turn up one's toes (virar os dedões para cima)

to be promoted to glory (ser promovido à glória to push up daisies (empurrar margaridas para cima)

to become a landowner (tomar-se proprietário de terras)

que encontram semelhantes em português:

$$
\begin{aligned}
& \text { morder o pó } \\
& \text { esticar as canelas } \\
& \text { ir para a glória } \\
& \text { comer grama por baixo } \\
& \text { desocupar o beco } \\
& \text { tocar harpa no céu }
\end{aligned}
$$

É contudo no âmbito da morte por enforcamento que encontramos divergências maiores. Os norte-americanos têm provérbios que enfatizam certos aspectos não existentes entre nós. É o caso do enforcamento como pena capital. Os disfemismos no caso são bastante irreverentes:

to dangle in the sheriffs frame (balançar na armadilha do xerife) to decorate a cottonwood (ornamentar uma paineira) to kick the bucket (chutar o balde) having a throat trouble (com problemas na garganta) doing a dance in mid-air (dançando no ar)
Não encontramos disfemismos em língua portuguesa que correspondessem aos acima. Acreditamos que seja pela razão de esta forma de punição não ser prática corrente entre nós. $O$ enforcamento, como:pena máxima, teve vida curta em nosso meio e sua vítimas são lembradas com sentimento religioso. Temos até uma Igreja dos Enforcados na cidade de São Paulo, para mencionar uma que conheço. Assim, traduzir ao pé da letra, não tem significado em português, a não ser que o contexto da ocorrência dirima qualquer dúvida. $O$ nosso "bater as botas", que parece ter alguma semelhança com to kick the bucket deveria suprir as ausências das demais. $O$ que não se pode fazer é misturar eufemismos com disfemismos. Estar com os anjos, ou no seio de Deus não serve para nenhum dos casos acima.

Traduzir provérbios ou expressões proverbiais não significa apenas encontrar o seu equivalente em dicionário especializado ou tentar uma tradução que mantenha os traços prosódicos, a concisão, rima e outros artificios desse tipo de texto. $\dot{E}$ preciso conhecer o seu emprego na língua de origem e saber que versão se adapta melhor à cultura da língua de chegada. A subdivisão em campos semânticos é uma grande ajuda para uma escolha que mais se aproxime do texto original.

\section{Referências bibliográficas:}

CAMARGO, S. \& STEINBERG, M. (1990) Euphemisms of Death in Translation. Comunicação apresentada no VIII Biennial Symposium on International Languages and Literatures, George Mason University, USA.

DUNDES, A. (1975) On the Structure of the Proverb. In: Proverbium, vol. 25, p. 961-973. [A observação de Archer Taylor foi um comunicação pessoal ao autor.]

GONÇALVES, D. (1977) Para uma Teoria Literária dos Ditados e Provérbios. In: Letras Hoje $\mathrm{n}^{\circ} 27$, março de 1977 , p. 72-80. 
GUSSOW, M.(1993) Gielgud comemora 90 anos com Rei Lear. O Estado de São Paulo- Cademo 2, 01/11/93, p. D 12.

KREIDLER, C. W. (1989) The Pronunciation of English, Oxford and New York, Basil Blackwell, p.6.

LADO, R. (1960) Linguistics across Cultures. Ann Arbor, Michigan, The U. of Michigan Press.
PAES, J. P. (1990) Tradução: A Ponte Necessária, São Paulo, Ática, p. 49-53.

STEINBERG, M. \& G.P.P. (Grupo de Pesquisa em Paremiologia), trabalho em andamento sobre Os Grandes Temas da Sabedoria Popular.

Apresentado em 1994. 
